$\gg$ epad

Vol. 2, N. 1, Abril/2018

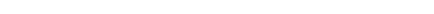




\title{
ENTRE A CASA E O BARRANCO: REFLEXÕES SOBRE A TIPOLOGIA DAS MULHERES PESCADORAS DE SANTO ANTÔNIO DE LEVERGER E BARÃO DE MELGAÇO
}

\section{BETWEEN THE HOUSE AND THE RIVER: REFLECTIONS ON THE TYPOLOGY OF THE FEMALE FISHERMEN FROM SANTO ANTÔNIO DE LEVERGER AND BARÃO DE MELGAÇO}

André Ribeiro Lacerda Instituto de Ciências Humanas e Sociais da Universidade Federal de Mato Grosso https://orcid.org/0000-0002-6145-4810

Patricia Cristiane de Souza Instituto de Computação da Universidade Federal de Mato Grosso https://orcid.org/0000-0003-4385-3751

\section{RESUMO}

Este trabalho apresenta duas tipologias sobre o perfil psicossocial de mulheres pescadoras para problematizar o crescimento das mulheres empreendedoras e chefes de família no Brasil. A partir das categorias das tipologias de Goffee e Scase (1985) e de Cromie e Hayes (1988), discute-se a situação das pescadoras de Santo Antônio do Leverger e Barão de Melgaço, se elas se enquadram ou não nas duas tipologias e se esse exercício pode contribuir para se entender a relação entre autoemprego e empreendedorismo. Foram feitas entrevistas estruturadas com pescadores profissionais no município de Leverger $(n=59)$ e Barão de Melgaço $(n=140)$ entre maio 2016 e dezembro de 2016. As entrevistas foram realizadas a partir do desenho de uma amostra por conglomerado em residências, local de venda de peixe e de pesca. Os resultados indicam que as duas tipologias devem ser adaptadas para a realidade das pescadoras, mas constituem bom ponto de partida.

Palavras-chave: autoemprego, empreendedorismo, mulheres pescadoras, tipologia.

\begin{abstract}
This paper presents two typologies of the psychosocial profile of female entrepreneurs aiming to problematize the increasing number of women entrepreneurs and female heads of households in Brazil. Based on the typology categories of Goffee and Scase (1985) and Cromie and Hayes (1988), the discussion deals with the situation of female fishermen of Santo Antônio do Leverger and Barão de Melgaço, whether or not they fit into the two typologies and if that exercise may contribute to understanding the relationship between self-employment and entrepreneurship. Data collected through structured interviews performed in 2016 are used to discuss the typologies.
\end{abstract}

Keywords: self-employment, entrepreneurship, female fishermen, typology. 


\section{INTRODUÇÃO}

Não há consenso na literatura que aborda o perfil psicossocial dos empreendedores sobre a relação entre empreendedorismo e autoemprego. Por exemplo, não está claro se a inovação é uma condição necessária ou se o trabalho por conta própria é suficiente, ou se o autoemprego e a propriedade de uma pequena empresa são igualmente empreendedores (GOFFEE; SCASE, 1983, 1985; CROMIE; HAYES, 1988; REYNOLDS, 1991; MARLOW, 1997; ASSUNÇÃO, 2012; CARROL; MOSAKOWSKI, 1987; SANTOS, 2014). De acordo com Navarro (2006), o conceito de autoemprego está relacionado ao profissional autônomo que presta serviços a outras pessoas ou instituições e que geralmente não precisa de muito dinheiro, constituindo-se de um empreendedorismo de baixo risco enquanto que o empreendedor geralmente precisa de um estudo de mercado (plano de negócios) e capital. Alguém que iniciou no mercado como autoemprego pode se transformar em um empreendedor a partir do momento em que amplia o seu negócio e passa a contratar funcionários ou incluir sócios. Para Navarro (2006, p. 9), "no autoemprego, você é a empresa, o empresário e o produto".

Um dado que tem chamado a atenção é o crescimento das mulheres que são empreendedoras em todo o mundo. Levantamento da Global Entrepreneurship Monitor (GEM) diz que em 2015, 51,2\% dos empreendedores que iniciaram negócios eram mulheres. No Brasil, essa proximidade entre os gêneros começou a ser atingida a partir de 2010. A título de comparação, em 2002, 57,6\% dos empreendedores iniciais eram homens e 42,4\%, mulheres; em 2015, 51\% dos empreendedores iniciais eram homens e $49 \%$ mulheres.

No Brasil, a Síntese dos Indicadores Sociais (IBGE, 2015) indicou que 40,5\% dos domicílios brasileiros têm a mulher como pessoa de referência. Desses, $41 \%$ são donas de negócios próprios. Os negócios iniciados por mulheres concentram-se em quatro áreas de atuação: restaurantes (16\%); serviços domésticos (16\%); cabelereiros (13\%) e comércio de cosméticos $(9 \%)$. A maior parte empreende dentro de casa. Segundo o conceito de Navarros (2006), há uma reflexão a se fazer: essas mulheres desenvolvem mais o autoemprego ou são empreendedoras?

Parece, portanto, que investigar o fenômeno do crescimento da participação das mulheres no mercado de trabalho pode ser um bom ponto de partida para se entender a relação e as interfaces entre autoemprego e empreendedorismo, em suas dimensões teórico e metodológica.

Reynolds (1991) afirma que os estudiosos do empreendedorismo têm se concentrado em investigar o empreendedor individual ou as atividades das suas empresas. O comportamento empreendedor individual geralmente se refere às atividades individuais de novos empreendimentos econômicos, que podem variar de autoempregos à criação de novas organizações.

No sentido das considerações feitas por Reynolds (1991), a sociologia e a psicologia social podem fazer algumas contribuições: (1) estudando as características societais específicas que afetam o empreendedorismo: processos sociais de modernização, papel do Estado no desenvolvimento econômico, variações no escopo e na natureza da economia informal; (2) investigando o caráter organizacional de certos grupos sociais e seus nichos ecológicos e em como esses nichos afetam novos fundamentos corporativos; (3) na investigação do impacto do contexto social sobre a decisão dos indivíduos que buscam empreender.

Quando se pretende investigar a relação entre indivíduos e estruturas sociais, parte-se do pressuposto de que a posição deles pode ser sintetizada em termos de seu conjunto de statuses, que são influenciados, em geral, pelo principal status do indivíduo no mundo contemporâneo, o status ocupacional e sua afiliação a organizações de trabalho. Visualiza-se 
os atores sociais desempenhando papéis em um status ocupacional, pois a sociedade humana é entendida como uma rede de statuses sociais (BIERSTEDT, 1957; TURNER, 2000; MARTIN, 2009).

Embora o ator social tome decisões racionais, a partir do significado que ele dá a suas metas, parte-se do pressuposto, por exemplo, que pescadores fazem avaliações a partir de parâmetros diferentes das pescadoras. Ou seja, o sexo constitui uma variável importante se há a pretensão de distinguir as escolhas em termos da ocupação de pescadores e pescadoras. A diferença reside nas extensões comportamentais das diferenças biológicas, conforme a sociologia evolucionista e a biossociologia têm demonstrado (SANDERSON, 2001; 2014).

Sociólogos e psicólogos sociais têm dado considerável atenção às decisões de carreira tomadas pelos indivíduos em suas situações sociais. Essas decisões incluem aquelas em relação à busca de autoempregos ou de criação de novas organizações. Algumas abordagens psicossociais têm investigado o contexto social dos indivíduos empreendedores, relacionandoos ao seu estágio de curso da vida, papel nos grupos sociais e background étnico.

Reynolds (1991) já tinha chamado a atenção para dois fenômenos que se tornaram ubíquos no mundo desenvolvido e em desenvolvimento: (1) as pequenas empresas e as atividades empreendedoras constituem agora uma característica significativa da maioria dessas sociedades; (2) a economia informal tem uma forte influência no comportamento empreendedor. Geralmente consiste em um grande número de empresas novas e pequenas que experimentam um nível significativo de turbulência por enfrentarem ou conviverem regularmente com nascimentos e mortes de empreendimentos.

Nos anos de 1990, cerca de 500 mil novas empresas eram iniciadas nos Estados Unidos e o tamanho médio da equipe inicial era de duas pessoas. Mais de um milhão de pessoas por ano estavam envolvidas na criação de novas empresas (startups), não incluindo os mais de nove milhões que trabalhavam por conta própria (autoemprego).

A escolha por empreender é uma importante opção ocupacional para um grande número de indivíduos. Isso leva diretamente à questão da importância de se identificar o perfil psicossocial de quem faz tal escolha e o porquê.

As decisões de aproveitar oportunidades são feitas quando as elas se apresentam. Se há poucas oportunidades e outros fatores limitarem as escolhas, o comportamento empreendedor será mais difícil.

Pela teoria da escolha racional, é possível dizer que os pretensos empreendedores fazem escolhas para viabilizar seus negócios. Esses negócios podem ser bem-sucedidos no curto, médio ou longo prazo. Entende-se que escolhas racionais estão relacionadas aos significados que eles dão aos seus objetivos e não em relação às metas em si mesmas (SANDERSON, 2001; ELSTER, 2007).

Desde os anos de 1980 tem ocorrido uma maior participação das mulheres no mercado de trabalho. Elas têm passado a desempenhar papéis ocupacionais antes restritos aos homens, como é o caso, por exemplo, da pesca no Pantanal.

Tunstall (1972) caracterizou a pesca como uma ocupação extrema, referindo-se à pesca marinha. No Pantanal, ela tem muitas das características da pesca fluvial brasileira com a especificidade de, no Pantanal, ser realizada em um ambiente em que o pescador corre risco de morte por compartilhar o ambiente natural de onças e cobras que representam ameaças à vida humana.

Atividade econômica antes restrita ao universo masculino, a pesca profissional tem incorporado um número expressivo de mulheres, conforme pode ser constatado na pesquisa realizada nas colônias de pescadores dos municípios de Santo Antônio de Leverger, Barão de Melgaço, Cáceres e Poconé. 
Entender porque essas mulheres escolhem a pesca como ocupação e que desafios elas enxergam nessa atividade econômica, permite entrar no universo das mulheres que participam do mercado de trabalho e muitas vezes são chefes de família. Elas podem ser ou não empreendedoras, podem apenas ter a carteira de pescadora para receber os quatro salários que o governo concede como seguro defeso na época da piracema, ou apenas usar a guia de pesca que permite, em certas situações, legalizar o comércio de peixe.

Quando se pensa na inserção das mulheres no mercado de trabalho, e em especial nas mulheres que escolhem gerir suas próprias ocupações, algumas questões teóricas se colocam: há diferenças em relação aos seus perfis psicossociais? E em relação a perfis como estado civil, se são mães e nível de escolaridade? Pode-se falar de um grupo ou perfis homogêneos?

\section{REFERENCIAL TEÓRICO}

A teoria da escolha racional refere-se aos significados que os atores sociais conferem à suas escolhas, aos significados que eles dão aos seus objetivos e não em relação às metas em si mesmas (SANDERSON, 2001; ELSTER, 2007). Partindo dessa perspectiva teórica, pretendese avaliar em que medida perfis psicossociais de mulheres classificadas como empreendedoras podem ser produtivos para se entender os diferentes perfis sociais das mulheres pescadoras e em que medida podem ser consideradas empreendedoras. Duas tipologias foram criadas a partir de investigações empíricas e serão objeto de escrutínio desse estudo: a de Goffe e Scase (1985) e Cromie e Hayes (1988).

Pode-se entender o aumento do número de mulheres empreendedoras como uma decorrência do impacto de processos de modernização sobre a estrutura da família. As atividades antes desenvolvidas pela mulher estavam circunscritas ao espaço doméstico. Com o aumento da participação delas no mercado de trabalho, vários espaços antes dominados pelos homens, passam a ter também a contribuição das mulheres.

Por exemplo, houve um incremento no número de mulheres na categoria de empreendedores estabelecidos, conforme dados apresentados na Tabela 1.

Tabela 1: Percentual da participação dos gêneros nos empreendimentos iniciais e estabelecidos no Brasil, período 2002-2015.

\begin{tabular}{|l|c|c|c|c|c|c|}
\hline & \multicolumn{2}{|c|}{2002} & \multicolumn{2}{c|}{2010} & \multicolumn{2}{c|}{2015} \\
\hline & Fem. & Masc. & Fem. & Masc. & Fem. & Masc. \\
\hline $\begin{array}{l}\text { Taxa de } \\
\text { Empreendedorismo Inicial } \\
\text { (TEA) }\end{array}$ & $42,4 \%$ & $57,6 \%$ & $49,3 \%$ & $50,7 \%$ & $49 \%$ & $51 \%$ \\
\hline $\begin{array}{l}\text { Taxa de } \\
\begin{array}{l}\text { Empreendedorismo } \\
\text { Estabelecido (TEE) }\end{array}\end{array}$ & $30,9 \%$ & $69,1 \%$ & $43,9 \%$ & $56,1 \%$ & $44,3 \%$ & $55,7 \%$ \\
\hline
\end{tabular}

Fonte: GEM (2015)

Goffee e Scase (1985) e Cromie e Hayes (1988) elaboraram tipologias de mulheres empreendedoras que constituem um bom ponto de partida para se pensar esse perfil psicossocial e a relação entre empreendedorismo e autoemprego, entre os diferentes contextos sociais e as motivações que levam os atores sociais a empreenderem ou não empreenderem.

Goffee e Scase (1985) defendem que, sendo empreendedoras, as mulheres explicitamente tentam evitar: (1) um mercado de trabalho que proporciona a elas ocupações inseguras e de baixa remuneração; (2) fortes controles de supervisão de emprego formal ou 
inibições que restringem o desempenho de seus papéis domésticos; (3) identidades impostas pelos homens, que são atribuídas por instituições sociais estabelecidas.

Parece, portanto, que criar seu próprio negócio pode ser uma estratégia viável, disponível para mulheres em suas tentativas de superar o mercado de trabalho e subordinação organizacional. E os dados sobre empregabilidade das mulheres têm sustentado que elas têm, cada vez, feito opção por essa escolha.

Goffee e Scase (1985) classificam a mulher empreendedora a partir de dois referenciais: (a) valores empresarias e (b) valores femininos convencionais. Sua tipologia identifica quatro perfis: as convencionais, as radicais, as inovadoras e as domésticas.

As convencionais têm alto compromisso tanto em relação a (a) valores empresariais quanto em relação a (b) valores femininos convencionais. As radicais têm baixo compromisso tanto em relação a (a) quanto em relação a (b). As inovadoras são fundamentalmente casadas e com valores empresariais, ou seja, têm compromissos relativos com (a) e (b). E as domésticas estão mais preocupadas com o papel doméstico, (b).

$\mathrm{Na}$ tipologia de Goffee e Scase (1985), as mulheres consideradas convencionais tentariam neutralizar a subordinação do mercado de trabalho. Elas são mais propensas a criar empresas principalmente com o objetivo de complementar a renda familiar. Essas mulheres eram essencialmente da classe trabalhadora. Eram casadas com maridos com empregos pouco seguros e mal remunerados. Entre as mulheres casadas, por exemplo, isso ajuda a superar os baixos salários dos maridos. As mulheres convencionais são motivadas pela necessidade de ganhar dinheiro e não por uma busca por maior autonomia pessoal e autossatisfação. Tendem a trabalhar em seu domicílio ou a ter um trabalho de tempo parcial.

As inovadoras procuram evitar a discriminação e dependência do mercado de trabalho. Elas criam seus negócios como um caminho para obter sucesso pessoal e econômico por causa de sua incapacidade de cumprir ambições dentro de uma estrutura organizacional convencional.

As radicais são aquelas mulheres que estão fundamentalmente interessadas em empreendimentos políticos e econômicos para promover questões femininas. Elas são ansiosas para superar o que classificam como subordinação social das mulheres.

As classificadas como domésticas ainda estão presas à domesticidade e desafiariam, de forma limitada, o primado do papel doméstico.

Cromie e Hayes (1988) construíram sua tipologia a partir de uma pesquisa realizada em Belfast, na Irlanda do Norte. De uma lista de nomes fornecidos por organizações de uma área comercial de Belfast, selecionaram potenciais entrevistados por um processo aleatório. Depois, telefonaram para as selecionadas para saber se estavam iniciando seus negócios ou se já estavam nele há mais de seis meses. Aquelas que tinham mais de seis meses em seus negócios foram descartadas. Cromie e Haeys (1988) verificaram que a amostra era heterogênea e que ter filhos era uma característica que distinguia significativamente as mulheres.

Diferentemente de Goffee e Scase (1985), Cromie e Haeys (1988) encontraram três perfis: as empreendedoras inovadoras, as dualistas e as reingressantes (retorners). Quatorze mulheres classificadas como inovadoras usavam seu negócio como um caminho positivo para desenvolver sua carreira. A média de idade delas era de 31 anos. Em relação ao estado civil, $33 \%$ eram casadas, $43 \%$ solteiras e $20 \%$ divorciadas. Só as divorciadas tinham filhos e os criavam em famílias monoparentais. Usavam seus pais como babás dos filhos.

Dez mulheres foram classificadas como dualistas. Nove delas fizeram progressos nas carreiras, principalmente em ocupações femininas tradicionais: fisioterapeuta superintendente, chefes de departamento de ensino, gerentes de pequenas organizações, enfermeiras chefes de equipe. A média de idade era de 30 anos, todas tinham filhos e eram casadas ou divorciadas. 
Para as dualistas, atender às necessidades dos filhos e ter algum emprego remunerado era crucial para elas. Segundo Cromie e Hayes (1988), as mulheres perceberam que ser proprietária do próprio negócio, permitiria maior flexibilidade do que a carreira organizacional convencional. Se as inovadoras estavam insatisfeitas, as dualistas não desejavam avançar mais na carreira, pois já tinham chegado ao lugar que queriam. O nome, dualistas, se refere ao desejo delas de preencher os dois papéis (domesticidade e valores empresariais). Diferentemente das inovadoras, para as dualistas, a autonomia e realização eram importantes, mas criar os filhos era um motivo de fundação.

Finalmente as reingressantes (retorners). Foram assim chamadas porque todas elas interromperam suas carreiras para ter e criar seus filhos. Algumas se retiraram do emprego remunerado para cuidar de filhos por anos; outras tiveram um filho e voltaram ao trabalho em tempo integral ou parcial, depois deixaram o trabalho para ter outro filho e assim por diante. As oito reingressantes tinham em média 41 anos de idade. Seis eram casadas com homens que tinham carreiras com curso superior e duas eram casadas com homens da classe trabalhadora, sem qualificação de curso superior. A maioria dessas mulheres buscava o emprego como uma satisfação pessoal.

Comparando as duas tipologias, Cromie e Hayes (1988) não encontraram em sua amostra as mulheres radicais de Goffee e Scase (1985). Aquelas que tinham alto compromisso com a domesticidade e o empreendedorismo são denominadas de convencionais por Goffee e Scase (1985) e dualistas por Cromie e Hayes (1988). Mas há diferenças significativas entre as duas classificações. As convencionais eram mulheres da classe trabalhadora, que eram forçadas a trabalhar por necessidade econômica e cuja renda era um complemento vital para o orçamento familiar. Elas eram impelidas pela necessidade de ganhar dinheiro e não pelo desejo de ganhar autonomia pessoal.

As dualistas, por outro lado, tinham carreira de sucesso e chegaram a um ponto em que podiam passar mais tempo com seus filhos. No trabalho por conta própria podiam atingir seus objetivos domésticos e empresariais.

As domésticas, de Goffee e Scase (1985), tinham forte compromisso com a família tradicional, sendo seu negócio circunscrito às demandas do sistema familiar doméstico. Seu compromisso com valores empresariais era fraco. As reingressantes também tinham fortes compromissos com papéis femininos tradicionais. Cromie e Hayes (1988) sugerem que talvez elas se assemelhassem às domésticas e apenas dirigissem seus negócios como um complemento com as preocupações em relação aos afazeres domésticos.

A duas tipologias indicam que há diferenças reconhecíveis entre as categorias de mulheres empreendedoras. Conforme, foi sublinhado no começo, não são rigorosas em relações a quesitos importantes na definição de empreendedorismo como inovação e autoemprego.

No Brasil, em um contexto em que o feminismo tem buscado fortalecer a emancipação da mulher e criado uma agenda política que busca reafirmar algumas conquistas e avançar em outras, a categoria de mulheres empreendedoras radicais talvez esteja presente, não necessariamente com os mesmos atributos encontrados por Goffee e Scase (1985), mas com um perfil afim.

As mulheres chefes de família monoparentais e de família biparental de baixa renda no Brasil parecem ter afinidade com três categorias das duas tipologias: as convencionais e as domésticas de Goffee e Scase (1985) e as reingressantes de Cromie e Hayes (1988).

As mulheres chefes de família biparentais podem ter características das mulheres convencionais, pois buscam complementar a renda familiar e são casadas com homens com empregos inseguros e de baixa remuneração. E podem se encaixar na categoria de reingressantes de Cromie e Hayes (1988), mas essa categoria parece ser mais aplicável a 
mulheres casadas de estrato socioeconômico não tão baixo, pois se a instabilidade do emprego dos maridos é alta, ela não pode se dar ao luxo de se restringir ao ambiente doméstico por um tempo, para cuidar dos filhos. A política de criação de creches pelas prefeituras pode estar introduzindo novas variações nessa categoria.

Mas, somente pesquisas empíricas poderão construir uma tipologia para a mulher brasileira que seja mais ou menos compatível com Goffee e Scase (1985) e Cromie e Hayes (1988).

As duas tipologias permitem fazer uma reflexão sobre a pesquisa empreendida com pescadores nos municípios de Santo Antônio do Leverger e Barão de Melgaço. E, talvez, entender porque uma ocupação antes praticamente restrita ao universo masculino vem sendo desempenhada também por mulheres e quem são essas mulheres.

A partir da perspectiva da teoria da escolha racional (SANDERSON, 2001; ELSTER, 2007), pretende-se avaliar como as duas tipologias apresentadas, permitem entender a situação das mulheres pescadoras dos municípios de Santo Antônio do Leverger e Barão de Melgaço.

\section{PROCEDIMENTOS METODOLÓGICOS}

Santo Antônio do Leverger e Barão de Melgaço são dois municípios com fortes características rurais. Ambos têm na agricultura de subsistência e na pesca suas atividades econômicas fundamentais. Leverger tinha população de 18.186 habitantes (estimativa do IBGE, 2016) e Barão de Melgaço 7.886 (estimativa do IBGE, 2016). Nas duas cidades, a pesca profissional e amadora são atividades econômicas influentes. Conforme dados levantados durante a pesquisa, a colônia de pescadores profissionais de Leverger tinha em 2016, cerca de 440 pescadores enquanto a de Barão de Melgaço tinha 1200 membros.

As pesquisas realizadas em Santo Antônio do Leverger e Barão de Melgaço não foram feitas com o objetivo de testar as tipologias apresentadas e nem de criar uma tipologia. $\mathrm{Na}$ verdade, o objetivo da pesquisa era descrever a estrutura sócio ocupacional dos pescadores do Pantanal Norte. Mas, produziram-se dados que permitem uma reflexão sobre as tipologias de mulheres empreendedoras, na medida em que se fizeram as seguintes perguntas: se a mulher pesca, se ela pesca sozinha, em dupla ou em grupo, estado civil, a profissão do esposo, o que ela fazia antes de ser pescadora, se tem filhos. Esses dados permitem iniciar uma reflexão sobre essas mulheres, que desenvolvem uma atividade de risco, antes restrita aos homens.

Entre a casa e o barranco, refere-se à situação social das pescadoras que têm filhos e que pescam nos barrancos perto de suas casas para que possam exercer, diariamente, funções domésticas como cuidar de filhos e da casa. Parecem se encaixar, portanto, dentro da categoria de domésticas na tipologia de Goffee e Scase (1985). Na tipologia de Cromie e Hayes (1988), as pescadoras não poderiam estar na categoria de empreendedoras inovadoras, e nem de dualistas e reingressantes, pois não parecem ter na pesca os objetivos de realização e satisfação profissional, nem compromissos com valores empresariais. Talvez tenham alguma coisa das mulheres reingressantes pelo compromisso com papéis tradicionais da mulher na estrutura da família.

Nossa hipótese geral é que as pescadoras estão mais próximas da categoria tipológica das domésticas de Goffee e Scase (1985): forte compromisso com a família tradicional, sendo seu negócio circunscrito às demandas do sistema familiar doméstico e fraco compromisso com valores empresariais. A intensidade com valores empresariais se manifestará fraca porque as 
pescadoras conduziriam seus negócios como um complemento de suas preocupações em relação aos afazeres domésticos e, geralmente, como subordinado ao trabalho do cônjuge, quando seu principal parceiro for o esposo.

E, baseado na descoberta de Cromie e Haeys (1988) de que a amostra que eles investigaram era heterogênea e que ter filhos era uma característica que distinguia significativamente as mulheres, formulou-se a seguinte hipótese: $h 1$ - pescadoras casadas com filhos pequenos tenderão a pescar perto e a desenvolverem a pesca como um apêndice do trabalho do marido, mais do que as pescadoras com filhos adultos ou sem filhos, que apresentarão maior autonomia.

Assim, realizaram-se entrevistas estruturadas - aplicadas na forma de survey - em Santo Antônio do Leverger (no texto também chamado simplesmente por Leverger) entre 20/05 a 24/06 de 2016 e em Barão de Melgaço entre 10/10 a 04/12 de 2016. Em Leverger, contabilizouse 59 entrevistas $(n=59)$. Apenas cinco $(n=5)$ mulheres foram entrevistadas em nossa amostra de mais de $10 \%$ da população (estimada pela colônia em cerca de 440 pescadores profissionais). Infelizmente, a colônia não quis informar quantas pescadoras estavam registradas. Em Barão de Melgaço, foram entrevistados 140 pescadores $(n=140)$, de uma população de 1200 . Trinta e oito $(n=38)$ mulheres estavam na amostra.

$\mathrm{O}$ questionário, aplicado na forma de entrevista, teve três blocos de questões. $\mathrm{O}$ primeiro, com 9 questões, visou introduzir a entrevistada no universo da pesquisa. O segundo bloco teve 23 questões e teve o objetivo de produzir os dados fundamentais que permitiriam verificar as hipóteses da pesquisa. E finalmente o terceiro bloco, com 11questões que coletou dados do perfil sócio demográfico das entrevistadas.

As entrevistas foram realizadas segundo o conceito de amostragem por conglomerados. Em cada município construiu-se um mapa dos locais de pesca e residência dos pescadores bem como lugares em que era possível encontrá-las. A partir desse mapa, e pelas informações dos presidentes das colônias sobre a proporção de pescadores em cada localidade, foi elaborado sub amostras em cada localidade. Os Gráficos 1 e 2 apresentam os locais em que as pescadoras foram entrevistadas.

Gráfico 1: Locais das entrevistas realizadas em Leverger $(\mathrm{n}=5)$

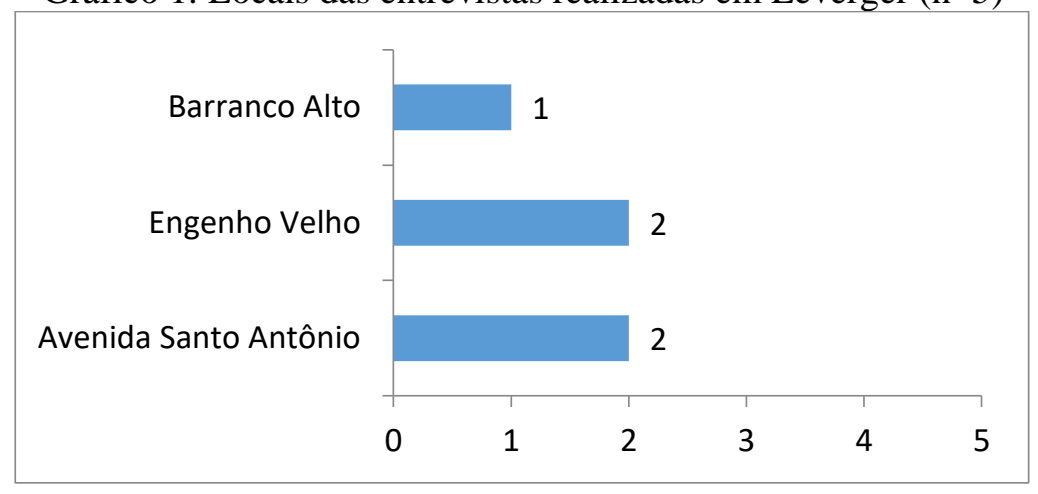

Fonte: Pesquisa de campo realizada no período de maio a junho de 2016 
Gráfico 2: Locais das entrevistas realizadas em Barão de Melgaço ( $n=38)$

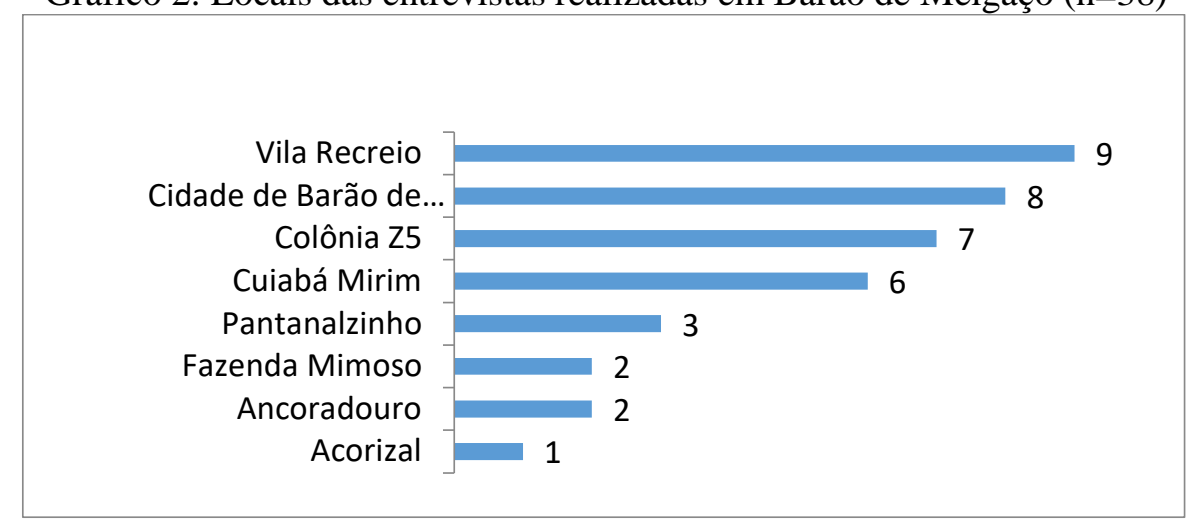

Fonte: Pesquisa de campo realizada no período de outubro a dezembro de 2016

Houve dificuldade em se ter acesso às mulheres pescadoras. Isso pode ter relação com as tipologias de Goffee e Scase (1985) e Cromie e Hayes (1988). Descartando-se o receio delas de que o pesquisador descobrisse que elas eram pescadoras em tempo parcial, havia também o medo, quando o pesquisador as encontrava, de que pudessem expor o marido, pois geralmente estavam na companhia dele e, nessas situações, somente ele concedia entrevistas. Então, a mulher-esposa preferia não se manifestar e, era perceptível, que o marido não concordava que ela se manifestasse. Pode-se argumentar que essas situações expressavam a condição de não independência dessas mulheres no que diz respeito às suas ocupações de pescadores e seus statuses sociais de esposa e mãe.

\section{RESULTADOS}

Os dados foram analisados para se verificar a hipótese geral de que as pescadoras estarão mais próximas da categoria tipológica das domésticas de Goffee e Scase (1985) com forte compromisso com a família tradicional, sendo seu negócio circunscrito às demandas do sistema familiar doméstico e fraco compromisso com valores empresariais.

Os Gráficos 3 e 4 apresentam dados que fazem vinculação com a ocupação que as mulheres desempenhavam antes de serem pescadoras. $\mathrm{O}$ objetivo é verificar se a ocupação anterior questiona a hipótese de que sua atividade estava subordinada às demandas do sistema familiar.

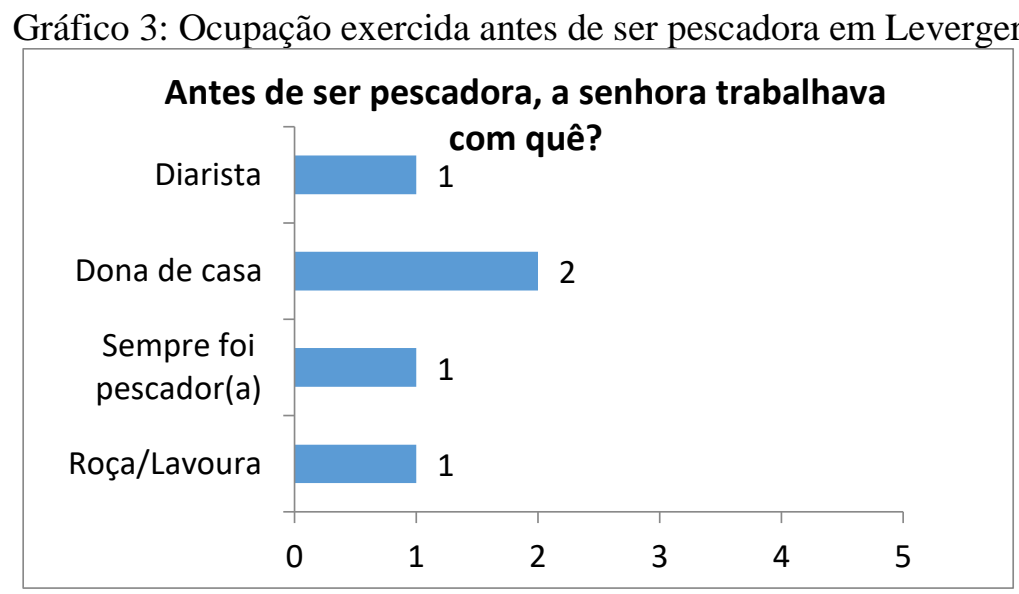

Fonte: Pesquisa de campo realizada no período de maio a junho de 2016 
Gráfico 4: Ocupação exercida antes de ser pescadora em Barão de Melgaço

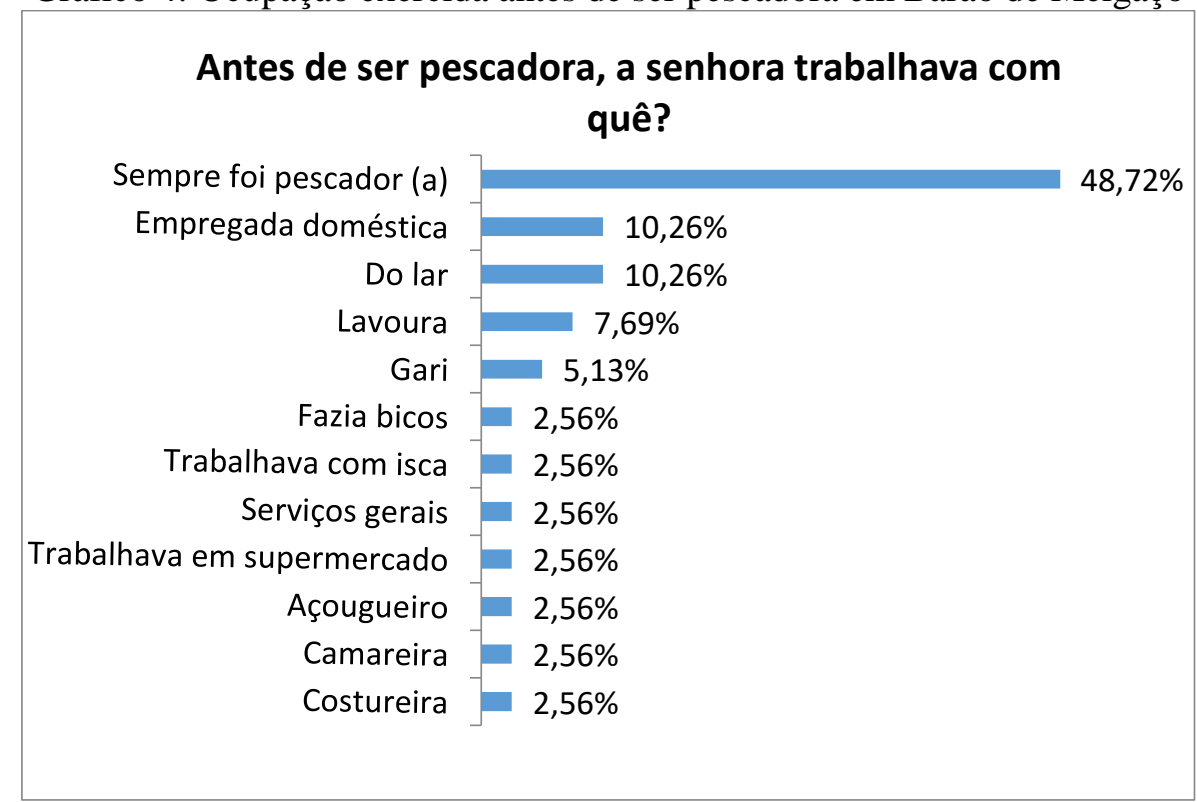

Fonte: Pesquisa de campo realizada no período de outubro a dezembro de 2016

Os dados, mais para Barão de Melgaço do que para Leverger, mostram que das atuais pescadoras, apenas 10,26\% desenvolviam atividades restritas ao espaço doméstico.

Os Gráficos 5 e 6 apresentam dados relativos à estratégia de pesca. As estratégias de pesca podem variar segundo as estações, as distâncias percorridas, e o tipo de peixe a ser capturado. Fundamentalmente, os Gráficos 5 e 6 apresentam dados sobre se as mulheres pescam sozinhas ou acompanhadas.

Gráfico 5: Como pescam as pescadoras de Leverger

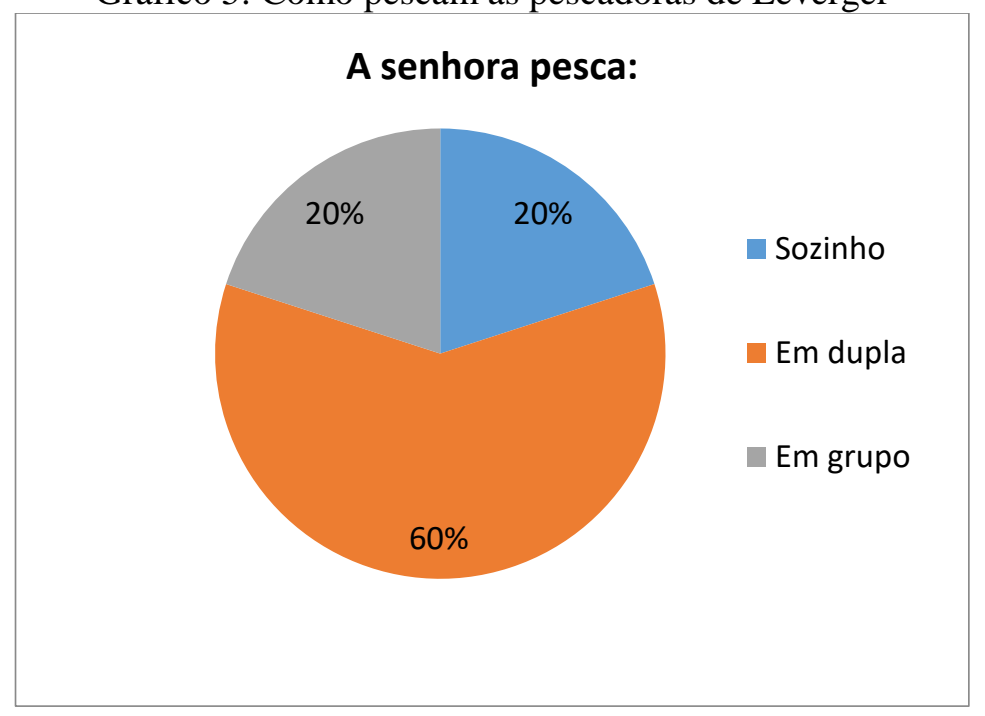

Fonte: Pesquisa de campo realizada no período de maio a junho de 2016 
Gráfico 6: Como pescam as pescadoras de Barão de Melgaço

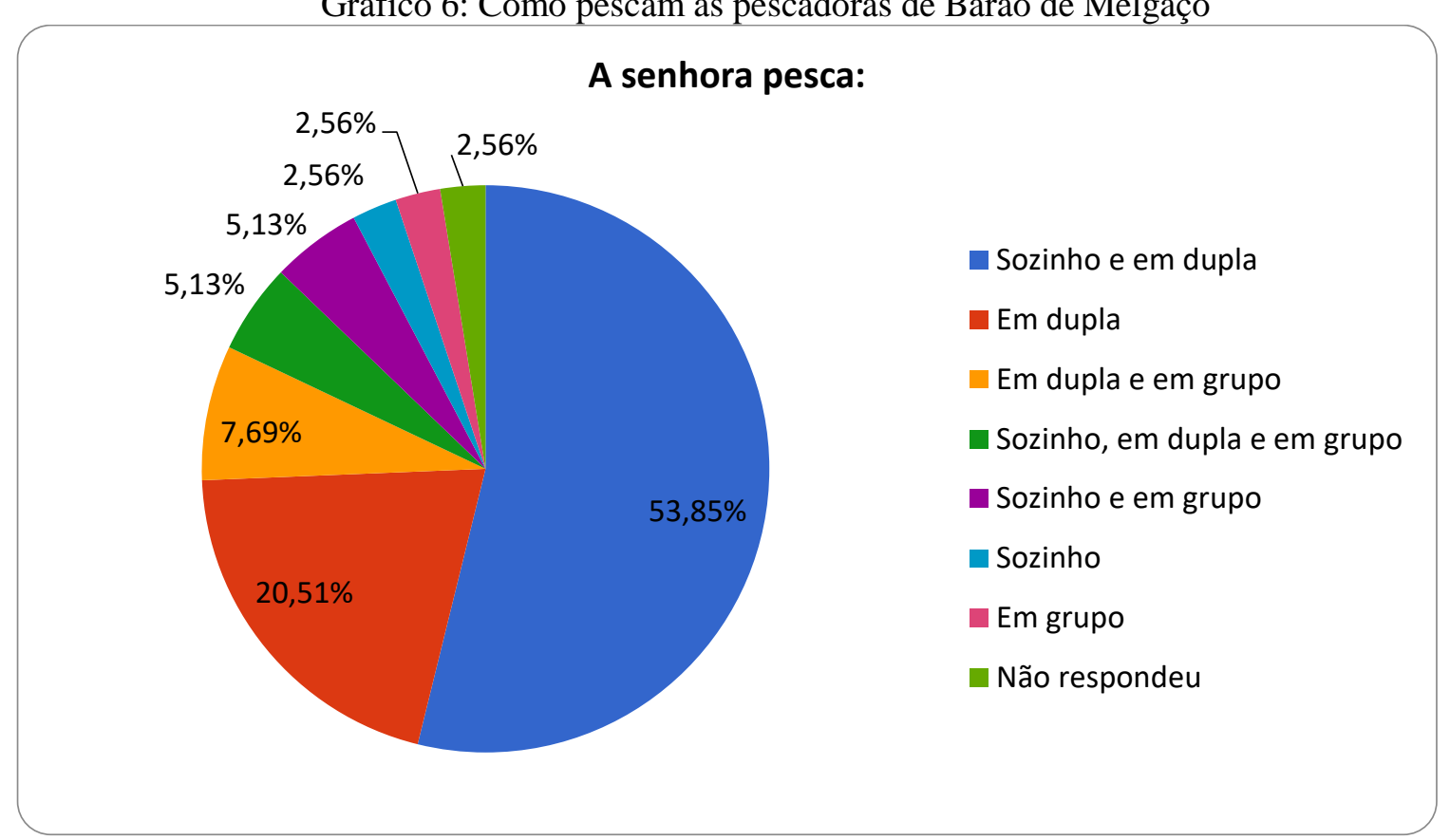

Fonte: Pesquisa de campo realizada no período de outubro a dezembro de 2016

Os dados mostram que a grande maioria das pescadoras não pesca sozinha.

Os Gráficos 7 e 8 procuram identificar, então, com que as pescadoras pescam, se não pescam sozinhas.

Gráfico 7: Com quem as pescadoras de Leverger pescam

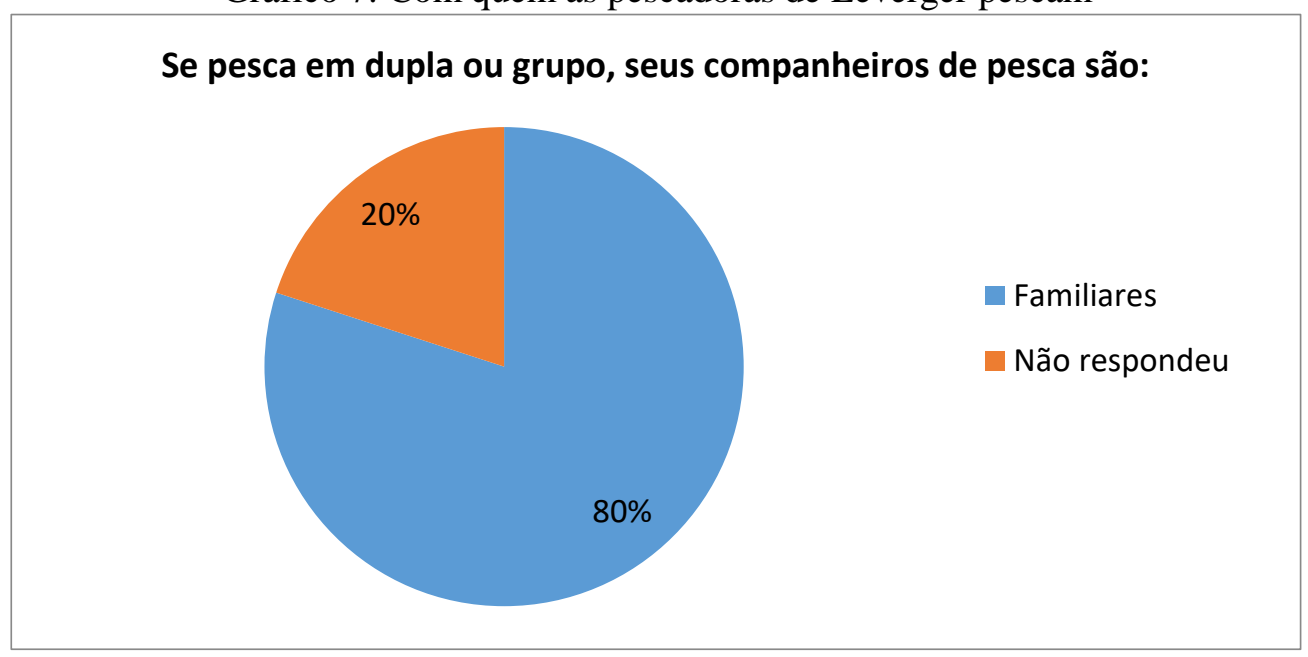

Fonte: Pesquisa de campo realizada no período de maio a junho de 2016 
Gráfico 8: Com quem as pescadoras de Barão de Melgaço pescam

\section{Se pesca em dupla ou grupo, seus companheiros de pesca são:}

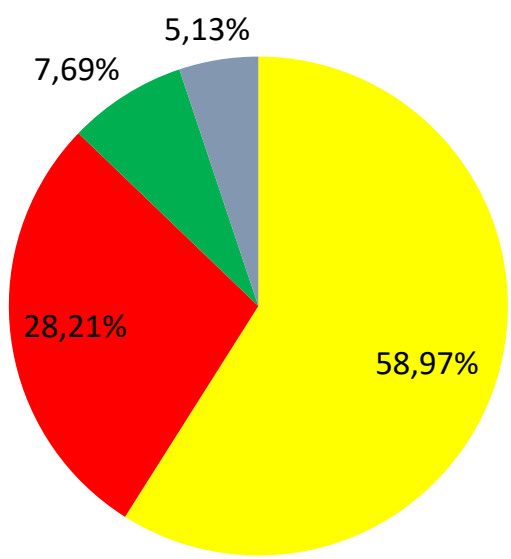

Familiares

Amigos e familiares

Amigos

Não respondeu

Fonte: Pesquisa de campo realizada no período de outubro a dezembro de 2016

Os dados dos Gráficos 7 e 8 mostram que a maioria das pescadoras escolhem como parceiros ou parceiras de pesca alguém do seu círculo familiar.

Foram elaboradas quatro Tabelas de Contingência (Tabelas 2 a 5) na tentativa de sustentar a hipótese 1 - pescadoras casadas com filhos pequenos tenderão a pescar perto e a desenvolverem a pesca como um apêndice do trabalho do marido, mais do que as pescadoras com filhos adultos ou sem filhos, que apresentarão maior autonomia.

Tabela 2: Filhos Adultos/Pequenos e Pesca Longe/Perto - Leverger

\begin{tabular}{|c|c|c|c|}
\hline & Filhos Adultos & Filhos Pequenos & Total \\
\hline Pesca longe & $01(20 \%)$ & $01(20 \%)$ & $02(40 \%)$ \\
\hline Pesca perto & $02(40 \%)$ & $01(20 \%)$ & $03(60 \%)$ \\
\hline Total & $03(60 \%)$ & $02(40 \%)$ & $05(100 \%)$ \\
\hline
\end{tabular}

Fonte: Dados do trabalho de campo realizado entre maio e junho de 2016

Tabela 3: Como Vai Pescar - Leverger

\begin{tabular}{|c|c|c|c|}
\hline & Filhos Adultos & Filhos Pequenos & Total \\
\hline Vai a pé/bicicleta & $03(60 \%)$ & $01(20 \%)$ & $04(80 \%)$ \\
\hline Vai de moto/carro & $00(0 \%)$ & $01(20 \%)$ & $01(20 \%)$ \\
\hline Total & $03(60 \%)$ & $02(40 \%)$ & $05(100 \%)$ \\
\hline
\end{tabular}

Fonte: Dados do trabalho de campo realizado entre maio e junho de 2016

Tabela 4: Filhos Adultos/Pequenos e Pesca Longe/Perto Barão Melgaço

\begin{tabular}{|c|c|c|c|}
\hline & Filhos Adultos & Filhos Pequenos & Total \\
\hline Pesca longe & $09(25 \%)$ & $07(19,44 \%)$ & $16(44,44 \%)$ \\
\hline Pesca perto & $06(16,66 \%)$ & $14(38,88 \%)$ & $20(55,55 \%)$ \\
\hline Total & $15(41,66 \%)$ & $21(58,33 \%)$ & $36(100 \%)$ \\
\hline
\end{tabular}

Fonte: Dados do trabalho de campo realizado entre outubro e dezembro de 2016 
Tabela 5: Como Vai Pescar - Barão Melgaço

\begin{tabular}{|c|c|c|c|}
\hline & Filhos Adultos & Filhos Pequenos & Total \\
\hline Vai a pé/bicicleta & $13(36,11 \%)$ & $16(44,44 \%)$ & $29(80,55 \%)$ \\
\hline Vai de moto & $03(8,33 \%)$ & $04(11,11 \%)$ & $07(19,44 \%)$ \\
\hline Total & $16(44,44 \%)$ & $20(55,55 \%)$ & $36100 \%)$ \\
\hline
\end{tabular}

Fonte: Dados do trabalho de campo realizado entre outubro e dezembro de 2016.

As quatro tabelas de contingências permitem relacionar as variáveis: mulheres com filhos pequenos/pescar perto e tipo de veículo de locomoção e pesca perto/pesca longe apenas para Barão de Melgaço, pois a amostra de pescadoras de Leverger, infelizmente, não é representativa.

\section{DISCUSSÃO}

Os dados sobre as mulheres pescadoras de Santo Antônio do Leverger não são representativos e, portanto, passíveis de generalização da situação da mulher pescadora em Leverger. Mas, as cinco (5) pescadoras desempenhavam funções compatíveis com o trabalho doméstico (Gráfico 3).

Em Barão de Melgaço, quase $80 \%$ das mulheres pescadoras trabalhavam em ocupações compatíveis com suas agendas domésticas, sempre pescadoras $(48,72 \%)$, geralmente pesca-se do lado de casa, empregada doméstica $(10,26 \%)$, do lar $(10,26 \%)$ e lavoura $(10,26 \%)$, segundo o Gráfico 4.

A grande maioria das pescadoras não pesca sozinha, conforme mostram os Gráficos $5 \mathrm{e}$ 6, 7 e 8 . Isto pode significar muitas coisas. A pesca é uma ocupação solitária, conforme mostra Tunstall (1972), mas em certas situações exige cooperação. No caso das mulheres, ou elas pescam com seus maridos, com seus filhos ou algum parente ou, em proporção menor, com alguma amiga. A pesca com o marido expressa cooperação, mas também que o trabalho dela é subordinado às ações dele em relação às iniciativas como coordenar a canoa, fazer armadilhas, pescar à noite.

Das trinta e oito (38) pescadoras entrevistadas, apenas duas (2) não tinham filhos. Por isso, as Tabelas de contingência trabalham com $n=36$. E das trinta e oito (38) pescadoras, quatro (4) não eram casadas ou viviam em união estável. Três (3) delas solteiras e uma (1) divorciada.

Por isso, não se elaborou uma tabela de contingência para comparar mulheres casadas/união estável com mulheres não casadas, pois a condição casada e com filhos não pareceu ser uma variável significativa para distinguir as mulheres pescadoras em relação a (a) valores empresarias e (b) valores femininos convencionais.

A relação entre a pescadora ser casada, ter filhos pequenos e pescar perto não se mostrou sustentável. Primeiro porque a concepção de perto e longe foi sub e superestimada. Como não foi controlada a subjetividade, ficou difícil utilizar essa categoria. Distingue-se as pescadoras com filhos pequenos das pescadoras com filhos adultos, mas em Leverger, ter filhos pequenos e pescar perto foi menos significativo do que ter filhos adultos e pescar perto (Tabela 1). Em Barão de Melgaço, a Tabela 2 mostra que 38,88\% das pescadoras com filhos pequenos vai pescar perto.

Para escapar da subjetividade dos entendimentos do que era perto e longe, optou-se por atrelar perto e longe aos tipos de locomoção utilizados. Aquelas pescadoras que vão a pé ou de bicicleta podem ser consideradas que pescam perto enquanto aquelas que se locomovem de carro ou moto pescariam longe. A Tabela 4 mostra que $80,55 \%$ das pescadoras de Barão de 
Melgaço pescam perto (vão a pé ou de bicicleta), o que parece um dado mais consistente do que a categorização de longe e perto.

\section{CONCLUSÃO}

As pescadoras profissionais de Leverger e Barão de Melgaço parecem se enquadrar na categoria tipológica das domésticas de Goffee e Scase (1985), com forte compromisso com a família tradicional, sendo seu negócio circunscrito às demandas do sistema familiar doméstico e fraco compromisso com valores empresariais. A intensidade com valores empresariais se apresenta fraca porque as pescadoras conduzem seus negócios como um complemento de suas preocupações em relação aos afazeres domésticos e, geralmente, como subordinado ao trabalho do cônjuge, quando sua parceria é com esposo.

$\mathrm{O}$ fato de muitas pescadoras exercerem sua ocupação parcialmente faz com que elas fiquem desconfiadas e não queiram conceder entrevistas, com medo de que sua situação questione a legitimidade de receber o seguro defeso e que ameace a contagem de seu tempo de serviço para aposentadoria. Mas, isso também expressa seu forte compromisso com os valores tradicionais da família, pois ela se divide entre os afazeres domésticos, a ocupação de pesca e, muitas vezes, alguma outra ocupação que dê a ela alguma renda e que possa ser desempenhada sem sair de casa, vender algo, por exemplo.

A pesquisa realizada não coletou dados que mensurassem a relação de dependência da esposa em relação ao marido, quando ambos são pescadores, pois se há uma hipótese que emerge das entrevistas é que, quando a pescaria é realizada pelo casal, a esposa tem papel secundário. Coletar esse dado seria interessante para se pensar uma escala na ocupação de pescadora e uma possível categorização no sentido de Goffee e Scase (1985) e Cromie e Hayes (1988).

Outras investigações também são passíveis de exploração como o comportamento empreendedor, que envolve, entre outras coisas, a noção de auto responsabilidade e a proatividade. Com o convívio nos ambientes dos pescadores, durante a etapa de coleta de dados, percebeu-se, de maneira bastante preliminar, que as pescadoras podem não ter a visão de que sua atividade pode ser considerada como autoemprego e que, elas podem, em busca de mais autonomia e rentabilidade, expandir suas atividades de forma empreendedora. Como por exemplo, desenvolver networking para criar novos canais de venda e distribuição de seus produtos.

As tipologias de Goffee e Scase (1985) e Cromie e Hayes (1988) podem ser referenciais produtivos para constituição de uma tipologia a ser testada entre mulheres que tem auto emprego no Brasil. As pescadoras, por estarem em um extremo em termos de condição socioeconômica e de especialização em termos ocupacionais, constituíram um bom desafio para as duas tipologias, mas o que fizemos foi um teste para as tipologias. Uma pesquisa exploratória, a partir de uma tipologia a ser testada poderia contribuir para uma compreensão dos desafios enfrentados pelas mulheres empreendedoras brasileiras.

\section{REFERÊNCIAS}

ASSUNÇÃO, F. M. de J. On Becoming self-employed: gender, class and entrepreneurship in Portugal. A thesis submitted to the University of Manchester in the Faculty of Humanities. Manchester, 2012.

BIERSTEDT, R. The Social Order. New York: McGraw-Hill, 1958. 
CARROL, G. R. e MOSAKOWSKI, E. M. The Career Dynamics of Self-Employment. Working Paper Series. Institute for Research on Labor and Employment, UC Berkeley, 1987.

CROMIE, S. e HAEYS, J. Towards a typology of female entrepreneurs. The Sociological Review. February, 1988.

ELSTER, J. La Explicacion del Comportamiento Social. Barcelona: Gedisa Editorial, 2007.

Global Entrepreneurship Monitor (GEM). Empreendedorismo no Brasil: 2015. (coordenação de Simara M. de S. S. Greco) Macedo, M. de M. et al. Curitiba: IBQP, 2014.

GOFFEE, R. e SCASE, R. Business ownership and women's subordination: a preliminary study of female proprietors. The Sociological Review. November.1, 1983.

GOFFEE, R. e SCASE, R. Women in Charge. London: Allen \& Unwin, 1985.

IBGE. Síntese dos Indicadores Sociais. Brasília: IBGE, 2015.

IBGE. Estimativa de População. Brasília: IBGE, 2016. Disponível online: https://www.ibge.gov.br/estatisticas-novoportal/sociais/populacao/9103-estimativas-depopulacao.html?=\&t=downloads. Acessado em: fev/2018.

MARLOW, S. Self-employed Women - new opportunities, old challenges? Entrepreneurship \& Regional Development. 9, pp 199-210, 1997.

MARTIN, J. L. Social Structures. Princenton: Princenton University Press, 2009.

NAVARro, L. O Auto Emprego é sua Carta na Manga. Coletânea sua Carreira, seu Sucesso. v. 3. São Paulo: Saraiva, 2006.

REYNOLDS, P. D. Sociology and Entrepreneurship. Disponível em: http://www.researchgate.net/publication/270820380.

SANDERSON, S. K. Human Nature and the Evolution of Society. Boulder, Colorado: Westview Press, 2014.

SANDERSON, S. K. The Evolution of Human Sociality. New York: Rowman \& Littlefield Publishers, Inc, 2001.

SANTOS, L. A. N. dos. Empreendedorismo Feminino em Portugal. (Dissertação de mestrado). Instituto Politécnico do Porto. Porto, 2014.

TUNSTALL, J. The Fishermen - The sociology of an extreme occupation. London: Macgibbon \& Kee London, 1972.

TURNER, J. H. Sociologia - conceitos e aplicações. São Paulo: Makron Books, 2000. 